\title{
When to start aripiprazole therapy in patients with bipolar mania
}

\author{
This article was published in the following Dove Press journal: \\ Neuropsychiatric Disease and Treatment \\ 13 March 2014 \\ Number of times this article has been viewed
}

\author{
Kiran Kumar Sayyaparaju' \\ Heinz Grunze' \\ Kostas N Fountoulakis ${ }^{2}$ \\ 'Newcastle University, Institute of \\ Neuroscience, Academic Psychiatry, \\ Newcastle upon Tyne, UK; ${ }^{2} 3$ rd \\ Department of Psychiatry, Division of \\ Neurosciences, School of Medicine, \\ Aristotle University of Thessaloniki, \\ Greece
}

\begin{abstract}
Aripiprazole is a third generation atypical antipsychotic with compelling evidence as a highly effective treatment option in the management of acute manic and mixed episodes of bipolar I disorders. It has a unique mode of action, acting as a partial agonist at dopamine D2 and D3, and serotonin 5-HT1A; and exhibiting antagonistic action at the 5-HT2A and H1 receptors. Overall, it has a favorable safety and tolerability profile, with low potential for clinically significant weight gain and metabolic effects, especially compared to other well-established treatments. It also has a superior tolerability profile when used as maintenance treatment. Side effects like headache, insomnia, and extrapyramidal side effects (EPSEs), such as tremor and akathisia may be treatment limiting in some cases. It is efficacious in both acute mania and mixed states, and in the long-term prevention of manic relapses. Aripiprazole therefore, is a significant player in the current portfolio of anti-manic pharmacological treatments. The data sources for this article are from EMBASE, MEDLINE, and the clinical trial database searches for all the literature published between January 2003 and September 2013. The key search terms were "aripiprazole" combined with "bipolar disorder", "mania", "antipsychotics", "mood stabilizer", "randomized controlled trial", and "pharmacology". Abstracts and proceedings from national and international psychiatric meetings were also reviewed, along with reviews of the reference lists of relevant articles.
\end{abstract}

Keywords: bipolar disorder, mania, maintenance, aripiprazole

\section{Introduction}

Bipolar disorder (BD) is a life-long and life-threatening illness, with a 12-month prevalence of $2.8 \%$, and contributed $£ 342$ million to the direct costs of the National Health Service in the UK in 2009. ${ }^{1}$

The full spectrum of BD consists of bipolar I and II disorders, cyclothymic disorder, substance/medication-induced bipolar and related disorder, bipolar and related disorder due to another medical condition, other specified bipolar and related disorder, and unspecified bipolar and related disorder (eg, hypomanic episodes not fulfilling time or symptom severity criteria, isolated hypomanic episode(s) without depression, or cyclothymia falling short of the time criterion of 24 months, etc). Mixed episodes which previously constituted a bipolar I subcategory on its own, are now described in the Diagnostic and Statistical Manual of Mental Disorders, fifth edition (DSM5) as a specifier "with mixed features" which can now be applied to mania, hypomania, or depression. ${ }^{2}$ Traditional cornerstones of the pharmacological treatment of BD have been lithium (LI) and some mood-stabilizing anticonvulsants, ie, carbamazepine, valproate (VAL), and lamotrigine. For the depressive phase of BD, antidepressants are widely
Correspondence: Heinz Grunze Newcastle University, Institute of Neuroscience, Academic Psychiatry, Campus of Aging and Vitality, Wolfson Research Centre, Westgate Road, Newcastle upon Tyne, UK

Tel +440 I9l 208 I372

Fax +4401912081387

Email heinz.grunze@ncl.ac.uk 
used, though their effectiveness remains controversial. ${ }^{3}$ In the last decade, however, second and third generation antipsychotics (SGA, TGA) have emerged as novel treatments for BD. Meanwhile, they are considered as standard treatment for mania ${ }^{4}$ and maintenance, ${ }^{5}$ and in the case of quetiapine, also for bipolar depression. ${ }^{6}$

Similar to the SGA, the TGA aripiprazole (ARI) was successfully tested in schizophrenia ${ }^{7}$ before pivotal studies in acute mania were conducted. Together with subsequent continuation and maintenance studies, we now have a very reasonable portfolio at hand that supports ARI effectiveness in BD. After reviewing the unique pharmacological profile of ARIs, this article will give a critical appraisal of the study portfolio, and considering additional aspects such as safety, tolerability, and impact on patient's quality of life, suggest an appropriate placement of aripiprazole in a modern bipolar treatment algorithm.

\section{Pharmacology of aripiprazole Pharmacodynamic data}

ARI is a partial agonist of dopamine D2/D3 and serotonin 5-HT1A receptors with modest antagonistic effects at 5-HT2A, 5-HT7, histamine $\mathrm{H} 1$ receptors, and moderate inhibitory action on serotonin reuptake. ${ }^{8-13}$ It blocks the occupancy of endogenous dopamine to its receptors and at the same time leads to partial dopamine receptor activation. This leaves $25 \%-30 \%$ of the maximal dopamine activity in the presence of ARI. ${ }^{14}$ A recent study showed the effects of ARI in stabilizing dopamine synthesis capacity. ${ }^{15}$ Its active metabolite, dehydro-aripiprazole, which has similar properties to the parent drug, contributes towards the overall effect. ${ }^{16}$ The net effects are a reduction of the overall transmission of dopamine in hyperdopaminergic regions of the brain, but unlike an antagonist, also a low tonic action in mesocortical areas. It also has moderate affinity for Alpha 1 - adrenergic and $\mathrm{H} 1$ receptors and negative affinity for muscarinic receptors. This may explain the lower risk associated with its use in the context of weight gain, sedation, and orthostatic hypotension. ${ }^{17,18}$ Its potential for QTc prolongation is comparable to that of placebo (PLB). ${ }^{19}$

\section{Pharmacokinetic data}

ARI is available in oral (tablet or liquid) and intramuscular (IM) formulations. It is well absorbed, with an oral bioavailability of $87 \%$, and can be taken without regards to food. It is highly protein bound, mainly to albumin (>99\%). ${ }^{12,19}$ It shows linear pharmacokinetics ${ }^{20,21}$ at therapeutic doses with peak plasma concentrations reached between 3-5 hours after ingestion and has a significantly longer half-life of 75 hours in comparison to other antipsychotics. This offers an advantage to patients in maintaining therapeutic blood levels in case they forget to take their medication in the short term. Steady state concentrations are achieved within 14 days of administration. When ARI injections were administered IM to healthy subjects, the median times to the peak plasma concentrations were 1 hour and 3 hours, with a $100 \%$ bioavailability being on average $19 \%$ higher than the maximum contration $\left(\mathrm{C}_{\max }\right)$ of the oral tablet. ${ }^{12,20}$

ARI is extensively metabolized in the liver by dehydrogenation and hydroxylation by cytochrome P450 CYP2D6 and N-dealkylation by cytochrome CYP3A4. ${ }^{12,19}$ It also does not induce or inhibit CYP2D6 or CYP3A4 enzymes and it does not influence the pharmacokinetics of VAL or LI. ${ }^{21}$ However, inducers or inhibitors of these enzymes will lead to a corresponding decrease or increase in plasma concentration of ARI. ${ }^{22}$ Poor metabolizers of CYP2D6 substrates (about 8\% of Caucasians), have about $80 \%$ higher exposure to ARI and about $30 \%$ lower exposure to dehydro-ARI, resulting in approximately $60 \%$ higher exposure to total active drug. ${ }^{12}$ Additionally, the elimination half-life is doubled (146 versus [vs] 75 hours) in poor metabolisers. ${ }^{12,19}$

Of those psychotropic medications which might be used in addition to ARI, only a few are prone to interactions. Through CYP 3A4 inhibition or induction, respectively, fluvoxamine could increase ARI serum levels, whereas carbamazepine will decrease ARI levels. In animal experiments, combined fluvoxamine and ARI resulted in hepatic damage. ${ }^{23}$ Duloxetine has been described as a moderate inhibitor of CYP2D6. However, coadministration of duloxetine and ARI does not seem to result in significant pharmacological or clinical adverse effects. ${ }^{24}$

What often seems to attract less attention when discussing pharmacokinetic interactions is the major human hepatic hydrolase, carboxylesterase 1 (hCES1), that serves as a target of metabolic inhibition by a variety of medications. Besides perphenazine, thioridazine, and fluoxetine, ARI was determined to be a potent hCES1 inhibitor. In mice, coadministration of ARI with the hCES1 substrate methylphenidate (MPH), commonly used in ADHD, but also treatment refractory depression, resulted in significantly increased MPH levels. ${ }^{25}$ So far, there have been no reports of this specific interaction in humans, but clinicians should be aware of this risk. Clinical signs of MPH intoxication usually include mydriasis, tremor, agitation, hyperreflexia, combative behavior, confusion, hallucinations, delirium, anxiety, paranoia, movement disorders, and seizures. 


\section{Acute manic phase studies}

ARI has been extensively studied in acute bipolar mania; selected studies are depicted in Table 1. The latest study of ARI in acute mania was a multi-center double-blind trial of Asian patients (Japan) that investigated the efficacy and safety of ARI ( $24 \mathrm{mg}$ /day) versus PLB for 3 weeks. Statistically significant mean improvements were noted from day 4 onwards to week 3 ( -11.3 vs -5.3 on the Young Mania Rating Scale [YMRS] at endpoint; last observation carried forward [LOCF] analysis). ${ }^{26}$ These results are in line with two earlier pivotal trials of ARI $30 \mathrm{mg}$ versus PLB conducted mainly in Caucasian populations. ${ }^{27,28}$ However, a further study comparing two fixed doses of ARI (15 mg, $30 \mathrm{mg}$ ) versus PLB in acutely relapsed, hospitalized patients did not show statistically significant separation of scores between the PLB and treatment groups. This was attributed to the unexpectedly high PLB response rate. ${ }^{29}$

A 30-week pediatric randomized controlled trial (RCT) compared ARI vs PLB for its acute anti-manic effects at 4 weeks $^{30}$ and its efficacy in the continuation phase at 30 weeks. ${ }^{31}$ It showed that both doses of ARI used, ie, $10 \mathrm{mg}$ and $30 \mathrm{mg}$, had superior anti-manic effects and had longer continuation times than PLB at both endpoints. In a wellpowered trial, both ARI and haloperidol (HAL) showed a significantly greater mean change in the YMRS compared to PLB at 3 weeks with comparable improvements at 12 weeks. ${ }^{32}$ In another study comparing ARI, LI, and PLB (1:1:1 randomization) for 3- and 12-week periods, ARI showed significant improvement in the mean YMRS score within 2 days. This improvement continued over 3 weeks and was sustained over 12 weeks, with a similar magnitude for both drugs. ${ }^{33}$

A randomized comparator trial against HAL and without a PLB arm found ARI being even more efficacious than HAL; however, this study was putting more weight on tolerability than efficacy and may not constitute a fair comparison. ${ }^{34}$ Finally, a small study comparing subjects on ARI versus olanzapine showed comparable changes in YMRS from baseline to day 15 in both groups without the need for increasing the dose of benzodiazepines in the ARI group. ${ }^{35}$ In summary, all the trials comparing ARI (doses of 15-30 mg) to established standard treatments showed comparable anti-manic efficacy, with an early and continued separation from PLB in YMRS scores and remission rates at 3 and 12 weeks, but with lower dropout rates in subjects taking ARI.

In an IM ARI study for the treatment of agitation in patients with bipolar I disorder, manic, or mixed episodes, subjects were randomized to four equally sized groups (about 75 each of IM ARI $9.75 \mathrm{mg}$, IM ARI $15 \mathrm{mg}$, IM lorazepam $2 \mathrm{mg}$, and IM PLB). Mean improvements in PANSS (Positive and Negative Syndrome Scale) Excited Component score at 2 hours were significantly greater with IM ARI $(9.75 \mathrm{mg},-8.7 ; 15 \mathrm{mg},-8.7)$ and IM lorazepam $(-9.6)$ versus IM PLB $(-5.8 ; P \leq 0.001)$. Both IM ARI doses were well tolerated; the safety profile was similar to oral ARI. ${ }^{36}$

Finally, ARI has demonstrated additional benefits adjunctive to LI or VAL in acute mania. Acutely manic patients partially non-responsive to MS alone and receiving combined treatment with ARI and one of the MS had a significantly higher reduction of their baseline YMRS score at week 6 (at study endpoint: -13.3 for ARI, -10.7 for PLB). Similar to the monotherapy studies, significant improvement in the YMRS total score with ARI versus PLB was observed from week 1 onward. ${ }^{37}$

\section{Continuation phase studies}

The 12-week acute phase study ${ }^{34}$ comparing ARI and LI was followed by a 40 -week continuation phase study. ARI monotherapy was equally useful compared to LI for the prevention of manic and mixed episode relapses, and had a similar time to discontinuation as well as time to relapse. ${ }^{38}$ Another study ( $n=337)$ evaluated the efficacy and safety of ARI adjunctive to LI or VAL (ARI+LI/VAL) compared with PLB adjunctive to LI or VAL (PLB+LI/VAL) for patients with bipolar I disorder who had an inadequate response to LI or VAL monotherapy at week 12 of the study. At week 52, the combination of ARI with the mood stabilizers (MS) was more favorable with a hazard ratio (HR) of 0.54 (95\% confidence interval [CI]: -0.33 to 0.89 ; log-rank $P=0.014$ [Kaplan-Meier relapse rate]). These findings suggest that there is benefit in continuing the ARI adjunctive to an MS after response to the acute phase treatment has been achieved. ${ }^{39}$ In a 52-week study, completers of a 6-week double-blind comparison of adjunctive ARI versus PLB in bipolar mania only partially responsive to LI or VAL monotherapy could enter a 46-week extension treatment with open-label adjunctive ARI plus LI (ARI+LI) or VAL (ARI+VAL). Significant improvements from baseline over the 52 weeks (LOCF) occurred with ARI+LI and ARI+VAL on the mean (95\% CI) YMRS total score $(-16.5[-18.1 ;-14.8]$ and $-17.6[-18.9 ;-16.3]$, both $P<0.001$ vs baseline) and Montgomery-Åsberg Depression Rating Scale (MADRS) total score $(-1.7[-3.3 ;-0.1]$, $P<0.05$ vs baseline vs $-2.7[-4.0 ;-1.4], P<0.001$ vs baseline).$^{40}$ In a study evaluating the efficacy and safety of ARI plus lamotrigine (LTG) $(n=178)$ compared with PLB 


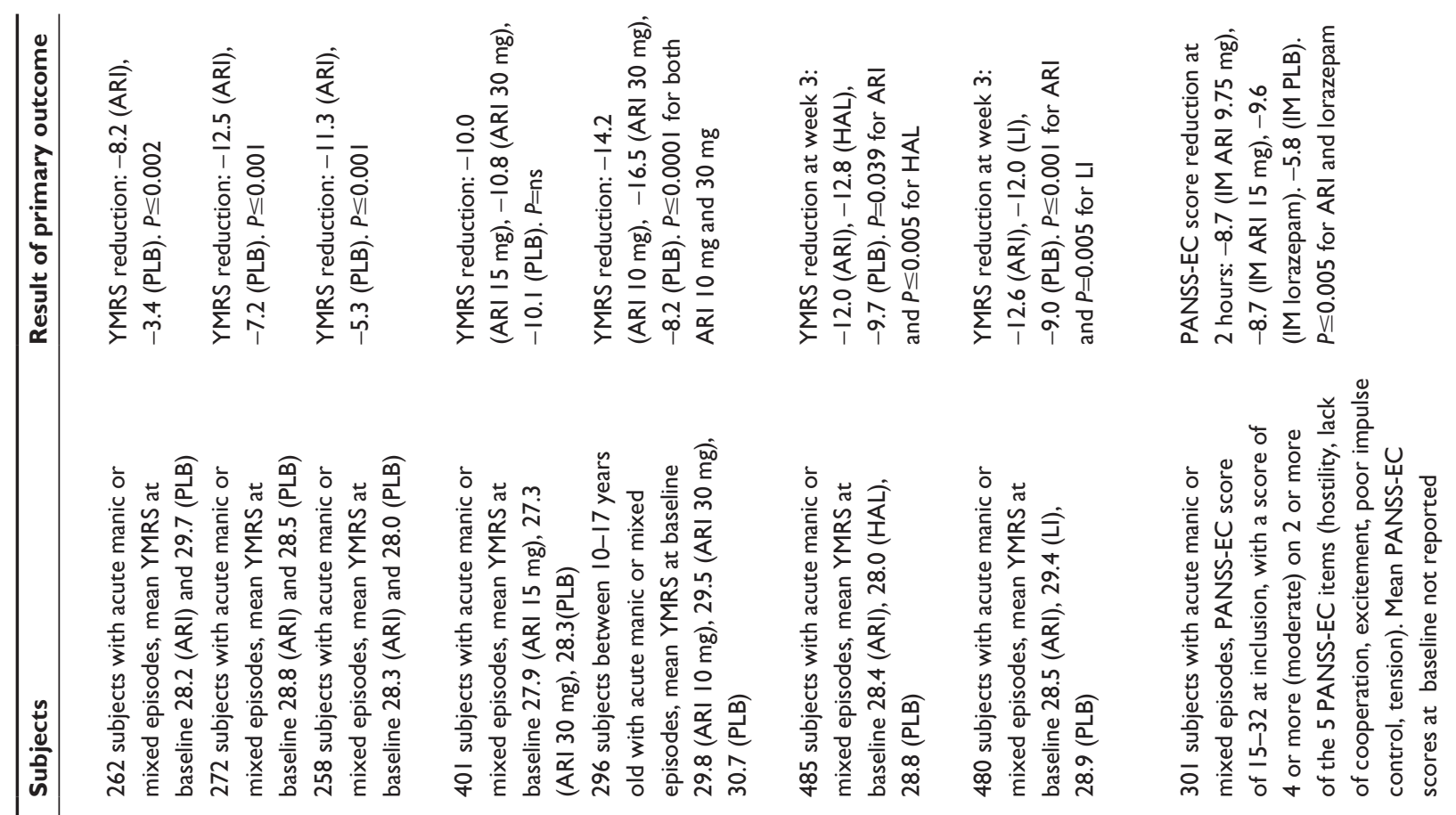

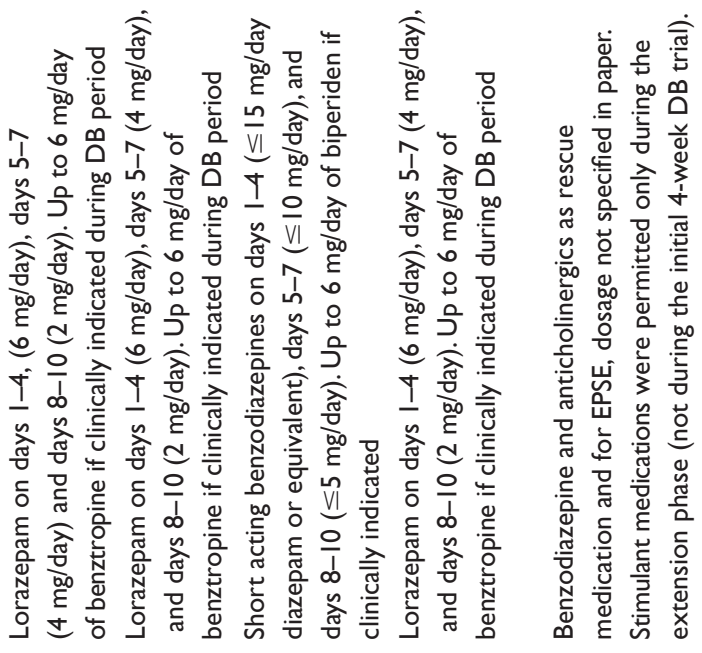

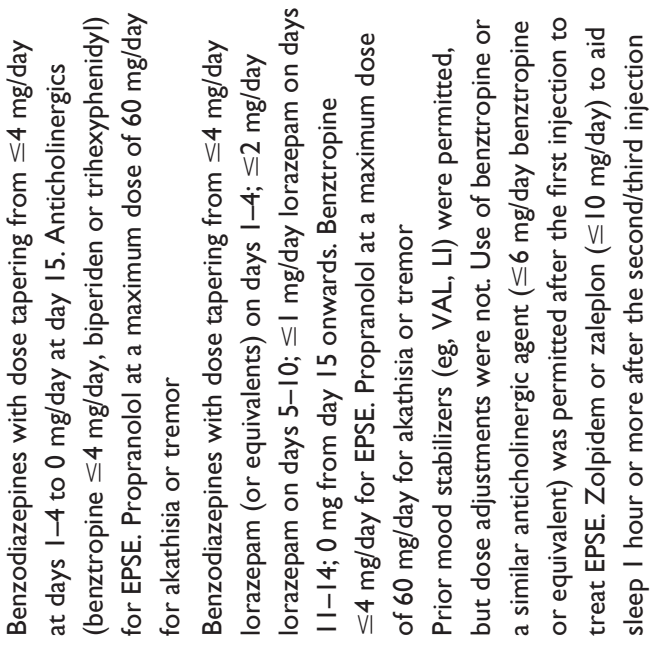

$\frac{\bar{\alpha}}{4}$

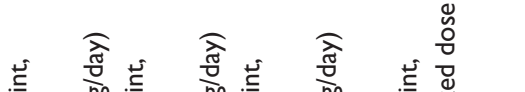

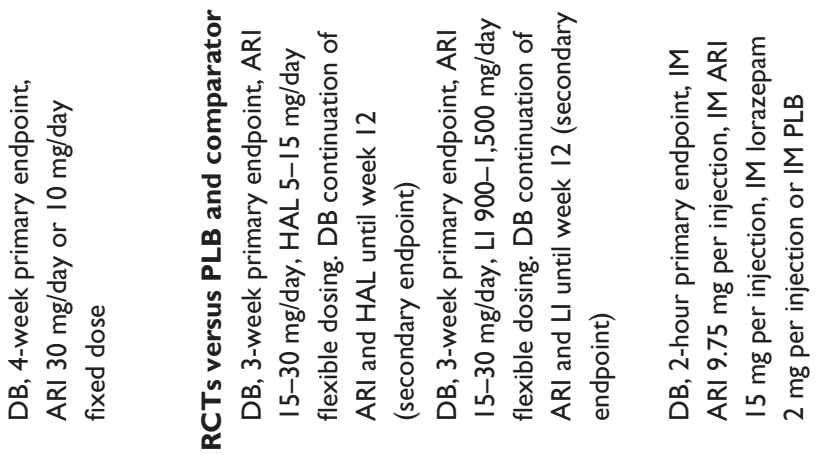

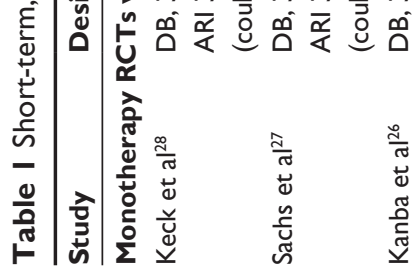

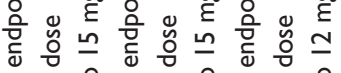

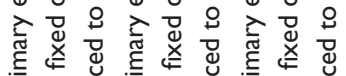

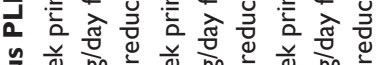

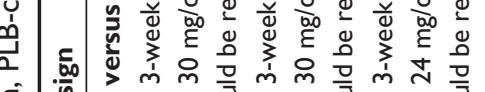

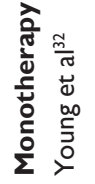

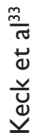

章 


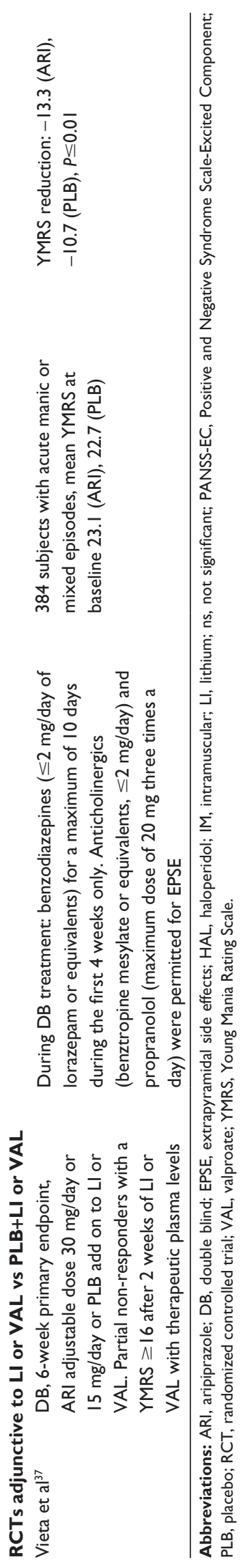

plus LTG ( $\mathrm{n}=173)$, the dual drug combination led to delay in the time to manic/mixed relapse which, however, did not reach statistical significance at week 52 (HR: $0.55 ; 95 \% \mathrm{CI}$ : $0.30-1.03 ; P=0.058) .{ }^{41}$

\section{Maintenance study}

A 26-week, double-blind, PLB-controlled relapse prevention study of $\mathrm{ARI}^{42}$ was followed by a prospective, 74-week, double-blind, PLB-controlled extension phase. Patients who achieved stabilization in the initial study continued for a further 74 weeks. At 100 weeks, the time to relapse was significantly longer with ARI $(\mathrm{N}=7)$ than PLB $(\mathrm{N}=5$; HR: 0.53; 95\% CI: $0.32-0.87 ; P=0.011$ ). ARI was superior to PLB in delaying time to a manic relapse (HR: $0.35 ; 95 \%$ CI: $0.16-0.75 ; P=0.005)$. The initial continuation treatment over 26 weeks demonstrated that ARI was effective for relapse prevention in patients who were initially stabilized with ARI for 6 consecutive weeks. However, between week 26 and 100, no further separation of survival curves for ARI and PLB occurred; thus, the study did not demonstrate a true long-term prophylactic effect of ARI. In addition, all conclusions from outcome data at week 100 were severely limited by the high attrition rate. ${ }^{43}$

\section{Meta-analysis and systematic reviews}

This section focuses on the meta-analyses comparing the efficacy of ARI versus PLB or other comparators. The metaanalyses of ARI monotherapy in acute mania by Fountoulakis et $\mathrm{a}^{44}(\mathrm{n}=2,303)$ included six trials which assessed the efficacy of ARI against acute manic/mixed episodes. ARI was superior compared to PLB or the comparator (HAL) in three of these studies. ARI was equally efficacious to comparators, ie, LI, HAL, and better than PLB in the other two studies. The pooled effect size at week 3 for ARI versus PLB was 0.34 . ARI had an NNT of 6 for response at 3 weeks and 12 for response at 12 weeks. NNT for remission at 3 and 12 weeks were 14 and 10, respectively. ${ }^{44}$ In an earlier review including six trials and looking into the use of ARI for psychotic symptoms in BD, the overall effect sizes for PANSS score reduction was 0.18 , with greater effect sizes for the positive subscale $(0.28)$ and the hostility subscale $(0.24) .{ }^{45}$ In a Cochrane database systemic review of 15 RCTs $(n=2,022)$ which included all SGAs and TGAs, ARI was superior to HAL which, in turn, was equal to olanzapine and risperidone where the risk ratio (RR) was 1.45 (95\% CI: $1.22-1.73) .{ }^{46}$ In a meta-analysis by Perlis et al ${ }^{47}(n=4,304)$ of 12 PLB-controlled 
monotherapy and 6 PLB-controlled adjunctive therapy trials, ARI, olanzapine, quetiapine, risperidone, and ziprasidone were equally effective against acute mania. ${ }^{47}$ These findings have been replicated by another meta-analytic study that excluded some studies in terms of effect sizes and the extracted data. ${ }^{48}$ A meta-analysis of 13 PLB-controlled RCTs of 3,089 subjects including two ARI studies showed an RR of 1.74 (95\% CI: $1.54-1.96)$ for ARI versus PLB. ${ }^{49}$ In a post hoc analysis based on two 3-week PLB-controlled trials of ARI in acute mania, ${ }^{27,28}$ subjects were classified as having either high or low scores of agitation at baseline. In highly agitated patients receiving ARI, PANSS-Excited Component (PEC) scores were significantly decreased versus PLB at endpoint. In patients with low agitation receiving ARI, no increases in PEC scores were seen, and a significant reduction in agitation symptoms was apparent after adjustment for baseline PEC scores. ARI-treated subjects had significantly greater reduction from baseline in YMRS total scores than PLB-treated subjects in both the high and low agitation groups $(P<0.05$ for both groups) and significantly improved Clinical Global Impression-Bipolar (CGI-BP) scores at endpoint in both $(P<0.05) .{ }^{50} \mathrm{~A}$ recent meta-analysis by Yildiz et $\mathrm{al}^{51}$ of studies in acute mania/mixed states of bipolar I (38 studies involving
10,800 patients allowing 56 drug-PLB comparisons of 17 different agents) showed that 13 drugs (76\%) were more effective than PLB with a pooled effect size of $0.42(95 \%$ CI: 0.36-0.48). The NNT for ARI was $6 .{ }^{51}$ Another recent analysis to ascertain the efficacy of SGAs and TGAs either as mono and/or adjunctive therapy in mixed episodes of BD included 9 RCTs with 1,289 mixed episode patients. This showed SGAs and TGAs to be equally effective, with combined effect sizes of 0.56 for pure manic episode and 0.44 for mixed episodes. ${ }^{52}$ A review of 24 studies $(n=6,187)$ of antipsychotic agents in the treatment of bipolar mania, came to the conclusion of the superior efficacy of ARI, amisulpride, clozapine, olanzapine, quetiapine, risperidone, ziprasidone, and zotepine, either in monotherapy or in combination with MS. Importantly, based on their review, the authors concluded that adding an antipsychotic to an MS was the most efficacious pharmacological treatment for acute mania. ${ }^{53}$

\section{Depot}

So far, data on ARI as an IM depot in BD have not been published. A recent large trial evaluated 576 schizophrenic subjects that entered IM-depot stabilization treatment after initial oral use of medication. Time to impending relapse

Table 2 Short- and long-term tolerability and safety of ARI in adults

\begin{tabular}{|c|c|c|c|}
\hline Study & AEs $\geq 5 \%$ and $\geq$ twice as frequent as with PLB & Discontinuation due to $\mathrm{AE}$ & Reports on severe AEs \\
\hline \multicolumn{4}{|l|}{ Acute mania studies } \\
\hline Keck et $\mathrm{al}^{28}$ & $\begin{array}{l}\text { ARI } 30 \text { mg/day: nausea ( } 23 \%) \text {, dyspepsia ( } 22 \%) \\
\text { somnolence ( } 20 \%) \text {, vomiting (I6\%), constipation (I3\%), } \\
\text { accidental injury ( } 12 \%) \text {, akathisia (I I \%) }\end{array}$ & $\begin{array}{l}6 \% \text { for ARI } 30 \mathrm{mg} / \text { day, } \\
5 \% \text { for PLB }\end{array}$ & $\begin{array}{l}\text { ARI } 30 \text { mg/day: } 4 \text { subjects } \\
\text { PLB: } 4 \text { subjects }\end{array}$ \\
\hline Sachs et $\mathrm{a}^{27}$ & $\begin{array}{l}\text { ARI } 30 \mathrm{mg} / \text { day: akathisia (I8\%), dyspepsia (15\%), } \\
\text { constipation (I2\%) }\end{array}$ & $\begin{array}{l}9 \% \text { for ARI } 30 \mathrm{mg} / \text { day, } \\
8 \% \text { for PLB }\end{array}$ & $\begin{array}{l}\text { ARI } 30 \mathrm{mg} / \text { day: } 12 \text { subjects } \\
\text { PLB: } 10 \text { subjects }\end{array}$ \\
\hline El-Mallakh et a ${ }^{29}$ & $\begin{array}{l}\text { ARI I } 5 \text { mg/day: akathisia ( } 14 \%) \text {, vomiting ( } 11 \%) \text {, } \\
\text { pain extremity ( } 8 \%) \\
\text { ARI } 30 \mathrm{mg} / \text { day: akathisia ( } 11 \%) \text {, pain extremity ( } 10 \%) \text {, } \\
\text { vomiting ( } 5 \%)\end{array}$ & $\begin{array}{l}7 \% \text { for ARI } 30 \mathrm{mg} / \text { day, } \\
15 \% \text { for ARI } 15 \mathrm{mg} / \text { day, } \\
7 \% \text { for PLB }\end{array}$ & $\begin{array}{l}\text { ARI } 30 \mathrm{mg} / \text { day: } 8 \text { subjects } \\
\text { ARI } 15 \mathrm{mg} / \text { day: I I subjects } \\
\text { PLB: } 10 \text { subjects }\end{array}$ \\
\hline Kanba et $\mathrm{al}^{26}$ & $\begin{array}{l}\text { ARI } 24 \mathrm{mg} / \text { day: akathisia }(22 \%) \text {, vomiting }(12 \%) \text {, } \\
\text { tremor (I } \%) \text {, nausea }(8 \%) \text {, salivary hypersecretion } \\
(7 \%) \text {, blood creatine phosphokinase increased }(7 \%)\end{array}$ & $\begin{array}{l}9 \% \text { for ARI } 24 \mathrm{mg} / \text { day, } \\
9 \% \text { for PLB }\end{array}$ & $\begin{array}{l}\text { ARI } 24 \text { mg/day: } 5 \text { subjects } \\
\text { PLB: } 9 \text { subjects }\end{array}$ \\
\hline \multicolumn{4}{|l|}{ Maintenance studies } \\
\hline Keck et al $(26 \text { weeks })^{42}$ & $\begin{array}{l}\text { ARI I5-30 mg/day: tremor ( } 9 \%) \text {, akathisia }(7 \%) \text {, } \\
\text { vaginitis }(6 \%) \text {, pain in extremities ( } 5 \% \text { ). } \\
\text { Weight gain } \geq 7 \% \text { of BL weight: } 13 \% \text { of ARI } \\
\text { subjects, } 0 \% \text { of PLB subjects }\end{array}$ & $\begin{array}{l}19 \% \text { for ARI } 15-30 \mathrm{mg} / \text { day, } \\
10 \% \text { for PLB }\end{array}$ & $\begin{array}{l}\text { ARI I } 5-30 \text { mg/day: } \\
6 \text { subjects } \\
\text { PLB: II subjects }\end{array}$ \\
\hline $\begin{array}{l}\text { Keck et al (extension } \\
\text { to } 100 \text { weeks) }{ }^{43, *}\end{array}$ & $\begin{array}{l}\text { ARI I5-30 mg/day: tremor ( } 9 \%) \text {, akathisia }(8 \%) \text {, } \\
\text { hypertension ( } 8 \%) \text {, dry mouth ( } 8 \%) \text {, weight gain }(7 \%) \text {, } \\
\text { vaginitis }(6 \%) \text {, abnormal thinking }(5 \%) \text {, pharyngitis }(5 \%) \text {, } \\
\text { flu syndrome }(5 \%) \\
\text { Weight gain } \geq 7 \% \text { of BL weight: } 20 \% \text { of ARI subjects, } \\
5 \% \text { of PLB subjects }\end{array}$ & $\begin{array}{l}28 \% \text { for ARI I } 5-30 \mathrm{mg} / \text { day, } \\
16 \% \text { for PLB }\end{array}$ & $\begin{array}{l}\text { ARI I } 5-30 \mathrm{mg} / \text { day: } \\
9 \text { subjects } \\
\text { PLB: } 19 \text { subjects }\end{array}$ \\
\hline
\end{tabular}

Notes: Data from selected short- and long-term PLB-controlled studies; ${ }^{*}$ numbers reported in the 100-week extension study are cumulative numbers, also including the figures reported for 26 weeks.

Abbreviations: AE, adverse events; ARI, aripiprazole; BL, baseline; PLB, placebo. 
was significantly delayed with ARI-IM-depot treatment compared with PLB in both the interim analysis and the final analysis $(P<0.0001, \log$-rank test $)$. ARI depot was safe and well tolerated in this study, which should encourage similar maintenance studies in BD. ${ }^{54}$

\section{Current guidelines}

Updated guidelines by the World Federation of Societies of Biological Psychiatry (WFSBP) for acute mania used six categories $(\mathrm{A}-\mathrm{F})$ based on levels of evidence for the scientific rigor of the literature. ARI was labeled A, ie, the highest category of efficacy for acute manic and mixed states. Also, given its superior tolerability profile, the highest recommendation grade of "1" was granted. Risperidone and VAL have also been given similar high ratings. ${ }^{4}$ Given that ARI has well-proven efficacy in relapse prevention of mania in patients with index episode of mania that responded to ARI, a recommendation grade of " 1 " was given for its longer term use. ${ }^{5}$ A 2012 UK panel consensus on the initiation of ARI for the treatment of acute mania agreed that ARI is effective both in the short- and long-term treatment of bipolar mania, either as monotherapy or in combination with an MS. Unlike other atypical agents, ARI has anti-manic effects that are not associated with sedation, and therefore may be more beneficial for selected patients, particularly in the long term. If rapid tranquillization is required when initiating ARI in acutely disturbed patients, short-term coprescription of a benzodiazepine is recommended. ${ }^{55}$ A 2013 update of the Canadian Network for Mood and Anxiety Treatments (CANMAT) guidelines for the management of patients with bipolar disorder recommends ARI as the first-line option for the treatment of acute mania either as monotherapy or as adjunctive therapy with LI or divalproex. ${ }^{56}$ The British Association of Psychopharmacology recommends oral administration of antipsychotic or VAL for patients not already on long-term treatment for BD because of their rapid anti-manic effects compared to LI. ARI is included in their recommendations as one of the atypicals with level 1 (highest grade) evidence for its effects in acute mania and mixed episodes. ${ }^{57} \mathrm{~A}$ critical review by an Italian group evaluating various trials and other evidence for the role of ARI in acute mania and long-term treatment of BD has shown ARI to be clinically effective in terms of response rates, remission rates, and prevention of relapse. They concluded that the efficacy and favorable metabolic profile of ARI make it a good option in the management of acute mania and maintenance treatment, with the added benefit of better treatment adherence rates, especially in an outpatient setting. ${ }^{58}$

\section{Tolerability}

A recent review pointed out ARI's favorable safety and tolerability profile, and minimal propensity for clinically significant weight gain and metabolic changes. EPSEs, however, may limit treatment in some cases. ${ }^{22}$ The most commonly reported adverse events (AEs) with ARI occurring in PLB-controlled trials are akathisia and nausea, each in $>3 \%$ of patients treated with oral ARI. ${ }^{59}$ The most common AEs that were considered to be treatment related and occurred twice as frequently in ARI compared to PLB during 3-week monotherapy were akathisia ( $13 \%$ vs $4 \%$ ), sedation ( $8 \%$ vs $3 \%$ ), restlessness ( $6 \%$ vs $3 \%$ ), tremor ( $6 \%$ vs $3 \%$ ), and EPSEs ( $5 \%$ vs $2 \%$ ). During 6 weeks of adjunctive therapy to MS, akathisia ( $19 \%$ vs $5 \%$ ), insomnia ( $8 \%$ vs $4 \%$ ), and EPSEs ( $5 \%$ vs $1 \%$ ) were most frequent. ${ }^{12}$ Two recurrence prevention trials for $52^{39}$ or $100^{43}$ weeks showed tremor, akathisia, hypertension, and dry mouth to be common side effects.

In a subgroup analysis of patients receiving adjunctive therapy, the most common treatment-emergent AE in ARI

Table 3 Indicators for the use of ARI in bipolar mania

Nature of disorder

Nature of disorder

Patient groups
Poor tolerability due to the following treatment-emergent side effects

When to consider ARI in acute mania

- Acute mania with mixed or psychotic episodes

- New onset and recurrent manic episodes

- Manic polarity of illness with a view on continuation treatment

- Switch option in subacute mania when considering long-term treatment

- Adjuvant treatment in cases of suboptimal response to monotherapy with MS
- Patients with need for rapid control of acute manic or mixed symptoms*

- Patient choice**

- Previous response to ARI

- Overweight and obese subjects

- High-risk group for metabolic syndrome, eg, past history or family history

- Patients with difficulties in adherence ${ }^{* * *}$
- Sedation

- Patients prone to weight gain

- Hyperprolactinemia

- Cognitive problems

- Dyslipidemia and metabolic disturbances

- Sensitivity to manifest EPSEs especially tardive dyskinesia

- QTc prolongation

Notes: *Consideration to the IM preparation should be given; **given the unique mode of action and significant differences in side-effect profile compared to other existing anti-manic treatments, introducing patients to choices of agents could lead to better treatment adherence; ***the long half-life of the oral formulation and availability of an IM depot makes it easier to maintain therapeutic serum levels.

Abbreviations: ARI, aripiprazole; EPSE, extrapyramidal side effects; IM, intramuscular; MS, mood stabilizers. 
plus LI versus ARI plus VAL groups were tremor (17\% vs $12.1 \%)$, gastrointestinal side effects $(10.4 \%$ vs $12.6 \%)$, weight gain (11.3\% vs $8.6 \%$ ), insomnia (9.4\% vs $10.3 \%)$, depression (7.5\% vs 9.2\%), akathisia (6.6\% vs $8.6 \%$ ), and headache (6.6\% vs 4.0\%). In the 100 -week ARI monotherapy trial, approximately twice as many subjects on PLB as on ARI had serious treatment-emergent AEs (23\% vs $12 \%)$ or withdrew from therapy because of treatment-emergent AEs ( $28 \%$ vs $16 \%$ ). This was largely due to worsening of manic or depressive symptoms in PLB recipients. ${ }^{43}$ Across all trials, the most common treatment-emergent AEs that led to treatment discontinuation in ARI recipients were mania in $1 \%{ }^{39}$ or manic reaction in $7 \%$ of patients, ${ }^{43}$ akathisia in $5 \%,{ }^{12,19}$ and tremor in $2 \%{ }^{60}$

\section{Extrapyramidal side effects}

EPSEs are dose related and occurred more often in ARI than PLB groups in both monotherapy and adjunctive therapy trials. The majority of AEs in ARI recipients were of mild or moderate severity during short-term monotherapy. ${ }^{27,28}$ There were no differences in symptom severity in the longer term monotherapy ${ }^{43}$ or adjunctive therapy. ${ }^{39}$ Pooled analysis of five 3-week monotherapy trials of ARI vs PLB showed no difference in EPS-related AEs when akathisia is excluded ( $9 \%$ ARI vs 7\% PLB); however, AE rates for akathisia just by itself were $18 \%$ for ARI and 5\% for PLB. ${ }^{60}$ Adjunctive treatment with ARI was also associated with a higher incidence of EPSE-related AEs compared to PLB recipients (28.1\% vs $13.8 \%)$. Of these, akathisia (18.6\% vs 5.4\%) and tremor $(9.1 \%$ vs $6.2 \%)$ were the most common AEs. ${ }^{37}$ Akathisia was generally mild or moderate with withdrawal rates of $2.3 \%$ versus $0 \%$ in ARI versus PLB groups in 3-week short-term therapy ${ }^{60}$ and $5.1 \%$ versus $0.8 \%$ during 6 -week adjunctive therapy. ${ }^{37}$ The onset of akathisia was usually during the early treatment phase with half of cases resolving by the end of study in 3-week trials ${ }^{60}$ and one-third of cases resolving in 6-week trials. ${ }^{37}$ Comparison of EPSEs during the first 3 weeks of a 12-week trial comparing ARI with LI showed 23\% versus $15 \%$ occurrence of these AEs. Akathisia was reported in $14.9 \%$ in ARI-treated patients, usually within the 3-week period. ${ }^{33}$ Akathisia (3.2\%) was the most common cause for treatment discontinuation in the ARI patients ${ }^{19}$ however, only two patients in a 100 -week monotherapy trial ${ }^{43}$ and two patients in 46-week extension of adjunctive trial ${ }^{40}$ discontinued because of akathisia.

\section{Weight changes}

In short-term trials of a 12 -week treatment period, there were no statistically significant differences in body weight between the ARI and LI (1.4 vs $0.3 \mathrm{~kg})^{33}$ or HAL groups $(0.7 \mathrm{vs} 0.56 \mathrm{~kg})^{32}$ and $(0.27 \mathrm{vs}-0.10 \mathrm{~kg}),{ }^{34}$ respectively. Generally, in most BD trials for maintenance either as monotherapy or adjuvant therapy, the mean body weight increased by $0.1-2.1 \mathrm{~kg}$ in ARI recipients versus -1.9 to $+0.6 \mathrm{~kg}$ in PLB recipients. There were no statistically significant changes in mean body weight from baseline. ${ }^{12,61}$ In a study of ARI as adjunctive to MS (LI or VAL) versus MS alone, there were no significant differences noticed with regards to weight gain $(+0.55 \mathrm{~kg}$ vs $+0.23 \mathrm{~kg}) .{ }^{37}$ However, during the 100-week maintenance phase of a recurrence prevention study of ARI monotherapy, significantly $(P=0.01)$ more ARI than PLB recipients had a clinically significant increase in body weight (20\% vs $5 \%$ ). Interestingly, further analysis of mean weight change in this study by body mass index (BMI) at baseline showed no significant difference in weight change observed between ARI and PLB for patients in both the low baseline BMI $\left(\leq 23 \mathrm{~kg} / \mathrm{m}^{2}\right)$ and high baseline BMI ( $\geq 27 \mathrm{~kg} / \mathrm{m}^{2}$ ) categories at study endpoint. ${ }^{43}$ However, a non-randomized trial of SGAs and TGAs in a juvenile cohort with a median duration of 10.8 weeks of treatment found a higher than expected weight gain for most atypicals. A $4.4 \mathrm{~kg}$ mean increase of body weight was associated with ARI $(n=41)$ compared to $0.2 \mathrm{~kg}$ in the untreated group $(\mathrm{n}=15) .{ }^{62}$ Table 2 depicts the tolerability and safety profile of ARI as observed in selected short- and long-term studies.

\section{Metabolic effects}

A metabolic syndrome (dyslipidemia, insulin-resistant diabetes, obesity, and hypertension) occurs at a significantly higher incidence in $\mathrm{BD}$ than in the general population. ${ }^{63}$ ARI is associated with a lower risk of metabolic and cardiac issues such as weight gain, diabetes, and dyslipidemia than most SGAs. ${ }^{64}$ In fact, a post hoc analysis of a 26-week study showed rates of metabolic syndrome with ARI comparable to PLB in patients with BD. ${ }^{65}$ There were no significant negative effects on metabolic parameters, ie, cholesterol, triglycerides, or glucose either in short term or long term in trials of ARI as monotherapy or in combination with LI or VAL. ${ }^{37,40,43}$ ARI is generally not associated with raised prolactin levels; therefore, chances of sexual dysfunction caused by this mechanism are low. ARI monotherapy may even be associated with a mean decrease in serum prolactin levels in patients coming off other antipsychotics. ${ }^{61}$ Two 3-week trials showed that the proportion of patients with mean serum prolactin levels above the upper limit of normal were actually lower in the ARI monotherapy than in the PLB group (11\% vs $17 \%) ;{ }^{28}$ (4\% vs $11 \%) .{ }^{27}$ The ARI group also showed lower increases 
in prolactin levels in the 12-week trials when compared with HAL (22.4\% vs $66.2 \%){ }^{32}$

Cardiovascular morbidity and mortality is of great concern in bipolar patients. ${ }^{66}$ The use of ARI is considered a safe option in patients at risk. The metabolic profile detailed above appears benign, and the use of $\mathrm{ARI}$ in $\mathrm{BD}$, especially in comparison with SGAs, did not raise any safety concerns as far as QTc prolongation is concerned. ${ }^{22,61}$

\section{When to start aripiprazole in bipolar mania}

Most of the current guidelines recommend the use of atypical antipsychotics for the treatment of manic symptoms. ${ }^{4,55-58}$ However, at least in the UK, ARI appeared to be used relatively infrequently as a first-line treatment for a long time. Besides pricing issues, this may be due to its non-sedative pharmacological profile and the perceived risks associated with treatment-emergent akathisia and EPSE symptoms. This may perhaps have led to an underuse of this effective treatment option despite its established efficacy in the trials, with a subsequent lack of clinical experience, and therefore, impacting confidence levels of prescribers to initiate antimanic treatment with ARI.

Well-powered trials evaluating its efficacy against PLB showed clear and continued separation in YMRS scores from day 2-4 onwards. ${ }^{26-28}$ The current evidence base supports its use in acute treatments from day 1 of an acute manic or mixed episode with good chances of timely response and remission. It is important to note that it also improves the depressive component of mixed episodes and not only the manic. ${ }^{44}$ This latter observation makes ARI a good first choice concerning the treatment of mixed episodes.

ARI should be considered as the first-choice agent in patients with obesity or metabolic disturbances, hyperprolactinemia, QTc prolongation, sensitivity to manifest EPSE, and especially tardive dyskinesia, or any other tendency to experience specific side effects caused by other SGAs (eg, sedation, cognitive disorder, etc). As obesity once manifest is difficult to combat and often irreversible, it may also be feasible to use ARI as a first-choice antipsychotic in patients only at risk of obesity, whether through lifestyle or genetic predisposition. Given the low propensity for ARI to cause sedation in the longer term, it is less likely to interfere with patients' cognition and level of functioning or quality of life.

As the choice of initial treatment of mania should already take continuity of treatment and long-term goals and outcomes into consideration, ${ }^{67}$ the most feasible time to initiate $\mathrm{ARI}$ is right at the acute episode and as early as possible in the course of BD.
IM injection of ARI may be considered in special circumstances, eg, in patients with high levels of agitation and lack of insight. If sedation is needed at this time, additional shortterm benzodiazepine treatment can be added and withdrawn as soon as possible.

Potential predictors for ARI response could be previous response and/or a manic polarity of the illness and the presence of mixed features. ${ }^{68} \mathrm{ARI}$ should be considered as a possible switch option during the subacute phase of mania and the continuation treatment if the initial medication has a high side-effect burden, especially unwanted sedation or metabolic issues. Slow cross-tapering is advised in this case. Using ARI as a primary prophylactic agent in euthymic, medication-free BD patients has not been studied so far. It may be considered in special cases, but is not backed up by evidence, eg, comparable to what is known for LI. Table 3 briefly summarizes when ARI could be considered as antimanic treatment of choice.

\section{Conclusion}

ARI has been shown to be both safe and effective in the treatment of acute manic and mixed episodes in acute and continuation stages of treatment. It also shows similar efficacy and a superior tolerability profile when compared against previously well-established treatments for acute mania. ${ }^{33,35,38-40}$ Given the lack of significant sedation, the addition of benzodiazepines can be considered in the first few days of treatment. ARI also has good quality evidence of its efficacy in the continuation and early maintenance phases of treatment for patients who have responded and been stabilized in the first few weeks of treatment. Overall, ARI is generally well tolerated. Akathisia, tremor, headache, dizziness, somnolence, sedation, fatigue, nausea, vomiting, and insomnia are some of the common side effects in the short term. ${ }^{37,43,59}$ These side effects, however, appear to be tolerable to most patients given the superior continuation rates of ARI versus PLB treatment, ${ }^{28,29}$ and equal or better tolerability profile compared to other active treatments. ${ }^{33,38,39}$ However, akathisia is a treatment-emergent side effect that is known to contribute to early treatment discontinuation in some patients. ${ }^{60}$ ARI has a superior side-effect profile in terms of sedation and weight gain, especially compared to well-established treatments like LI, VAL, and also most of the atypical antipsychotics. With its lower incidence of dyslipidemia, treatment-emergent diabetic symptoms, and changes of prolactin levels, ${ }^{37,43,63-65}$ ARI is a safe treatment choice given the need to continue effective drug treatments in $\mathrm{BD}$ in the long term.

\section{Disclosure}

Dr Sayyaparaju received no support, grants, or sponsorships from any pharmaceutical companies or other organizations. 
Dr Grunze has received grants/research support, consulting fees, and honoraria within the last 3 years from AstraZeneca, BMS, Otsuka Pharmaceuticals, Desitin, Eli Lilly, Gedeon Richter, Hoffmann-La Roche, Lundbeck, Merck, Servier, and UBC. Dr Fountoulakis is/was a member of the International Consultation Board for various pharmaceutical companies and has received honoraria for lectures from AstraZeneca, Janssen-Cilag, and Eli-Lilly and research grants from AstraZeneca and Pfizer Foundation. He has received support for attending congresses by Janssen, BMS, Eli Lilly, Pfizer, AstraZeneca, and others. The authors report no other conflicts of interest in this work.

\section{References}

1. Young AH, Rigney U, Shaw S, Emmas C, Thompson JM. Annual cost of managing bipolar disorder to the UK healthcare system. J Affect Disord. 2011;133:450-456.

2. American Psychiatric Association. Diagnostic and Statistical Manual of Mental Health Disorders: DSM-5. 5th ed. Washington, DC: American Psychiatric Publishing, 2013.

3. Pacchiarotti I, Bond DJ, Baldessarini RJ, et al. The International Society for Bipolar Disorders (ISBD) task force report on antidepressant use in bipolar disorders. Am J Psychiatry. 2013;170(11):1249-1262.

4. Grunze H, Vieta E, Goodwin GM, et al. The World Federation of Societies of Biological Psychiatry (WFSBP) guidelines for the biological treatment of bipolar disorders: update 2009 on the treatment of acute mania. World J Biol Psychiatry. 2009;10:85-116.

5. Grunze H, Vieta E, Goodwin GM, et al. WFSBP Task Force on Treatment Guidelines for Bipolar Disorders. The World Federation of Societies of Biological Psychiatry (WFSBP) guidelines for the biological treatment of bipolar disorders: update 2012 on the longterm treatment of bipolar disorder. World J Biol Psychiatry. 2013;14: 154-219.

6. Grunze H, Vieta E, Goodwin GM, et al. WFSBP Task Force On Treatment Guidelines For Bipolar Disorders. The World Federation of Societies of Biological Psychiatry (WFSBP) guidelines for the biological treatment of bipolar disorders: update 2010 on the treatment of acute bipolar depression. World J Biol Psychiatry. 2010;11:81-109.

7. Park MH, Han C, Pae CU, et al. Aripiprazole treatment for patients with schizophrenia: from acute treatment to maintenance treatment. Expert Rev Neurother. 2011;11:1541-1552.

8. Burris KD, Molski TF, Xu C, et al. Aripiprazole, a novel antipsychotic, is a high-affinity partial agonist at human dopamine D2 receptors. J Pharmacol Exp Ther. 2002;302:381-389.

9. Jordan S, Koprivica V, Chen R, et al. The antipsychotic aripiprazole is a potent, partial agonist at the human 5-HT(1A) receptor. Eur $J$ Pharmacol. 2002;441:137-140.

10. Shapiro DA, Renock S, Arrington E, et al. Aripiprazole, a novel atypical antipsychotic drug with a unique and robust pharmacology. Neuropsychopharmacol. 2003;28:1400-1411.

11. Keck PE Jr, McElroy SL. Aripiprazole: a partial dopamine D2 receptor agonist antipsychotic. Expert Opin Investig Drugs. 2003;12(4): 655-662.

12. Abilify ${ }^{\circledR}$ (aripiprazole) [US prescribing information] (online). New York: Bristol-Myers Squibb. Available from: http://www.accessdata.fda.gov/ drugsatfda_docs/label/2013/021436s037,021713s029,021729s021,021 866s022lbl.pdf. Accessed September 27, 2013.

13. Tadori Y, Forbes RA, McQuade RD, Kikuchi T. Characterization of aripiprazole partial agonist activity at human dopamine D3 receptors. Eur J Pharmacol. 2008;597(1-3):27-33.

14. Gründer G, Kungel M, Ebrecht M, Göröcs T, Modell S. Aripiprazole: pharmacodynamics of a dopamine partial agonist for the treatment of schizophrenia. Pharmacopsychiatry. 2006;39 Suppl 1:S21-S25.
15. Ito H, Takano H, Arakawa R, et al. Effects of dopamine D2 receptor partial agonist antipsychotic aripiprazole on dopamine synthesis in human brain measured by PET with L-[ $\beta-11 C]$ DOPA. PLoS One. 2012;7(9):e46488.

16. Tadori Y, Forbes RA, McQuade RD, Kikuchi T. In vitro pharmacology of aripiprazole, its metabolite and experimental dopamine partial agonists at human dopamine D2 and D3 receptors. Eur J Pharmacol. 2011;668(3):355-365.

17. Takahata K, Ito H, Takano H, et al. Striatal and extrastriatal dopamine $\mathrm{D}_{2}$ receptor occupancy by the partial agonist antipsychotic drug aripiprazole in the human brain: a positron emission tomography study with $\left[{ }^{11} \mathrm{C}\right]$ raclopride and $\left[{ }^{11} \mathrm{C}\right]$ FLB457. Psychopharmacology (Berl). 2012;222(1):165-172.

18. Miller D. Atypical antipsychotics: sleep, sedation, and efficacy. Prim Care Companion J Clin Psychiatry. 2004;6(Suppl 2):3-7.

19. Abilify ${ }^{\circledR}$ (aripiprazole): summary of product characteristics (online). London: European Medicines Agency. Available from: http://www. ema.europa.eu/docs/en_GB/document_library/EPAR_-_Product_Information/human/000471/WC500020170.pdf. Accessed September 27, 2013.

20. Mallikaarjun S, Salazar DE, Bramer SL. Pharmacokinetics, tolerability, and safety of aripiprazole following multiple oral dosing in normal healthy volunteers. J Clin Pharmacol. 2004;44(2):179-187.

21. Boulton DW, Kollia GD, Mallikaarjun S, Kornhauser DM. Lack of a pharmacokinetic drug-drug interaction between lithium and valproate when co-administered with aripiprazole. J Clin Pharm Ther. 2012;37: 565-570.

22. McIntyre RS, Soczynska JK, Woldeyohannes HO, Miranda A, Konarski JZ. Aripiprazole: pharmacology and evidence in bipolar disorder. Expert Opin Pharmacother. 2007;8(7):1001-1009.

23. Shastry CS, Shafeeque AA, Ashwathnarayana BJ. Effect of combination of aripiprazole with carbamazepine and fluvoxamine on liver functions in experimental animals. Indian J Pharmacol. 2013;45: $121-125$.

24. Hendset M, Molden E, Enoksen TB, Refsum H, Hermann M. The effect of coadministration of duloxetine on steady-state serum concentration of risperidone and aripiprazole: a study based on therapeutic drug monitoring data. Ther Drug Monit. 2010;32:787-790.

25. Zhu HJ, Appel DI, Peterson YK, Wang Z, Markowitz JS. Identification of selected therapeutic agents as inhibitors of carboxylesterase 1: potential sources of metabolic drug interactions. Toxicology. 2010;270: $59-65$.

26. Kanba S, Kawasaki H, Ishigooka J, Sakamoto K, Kinoshita T, Kuroki T. A placebo-controlled, double-blind study of the efficacy and safety of aripiprazole for the treatment of acute manic or mixed episodes in Asian patients with bipolar I disorder (the AMAZE study). World J Biol Psychiatry. Epub April 30, 2012.

27. Sachs G, Sanchez R, Marcus R, et al; Aripiprazole Study Group. Aripiprazole in the treatment of acute manic or mixed episodes in patients with bipolar I disorder: a 3-week placebo-controlled study. J Psychopharmacol. 2006;20(4):536-546.

28. Keck PE Jr, Marcus R, Tourkodimitris S, et al; Aripiprazole Study Group. A placebo-controlled, double-blind study of the efficacy and safety of aripiprazole in patients with acute bipolar mania. $\mathrm{Am} \mathrm{J}$ Psychiatry. 2003;160(9):1651-1658.

29. El-Mallakh RS, Vieta E, Rollin L, Marcus R, Carson WH, McQuade R. A comparison of two fixed doses of aripiprazole with placebo in acutely relapsed, hospitalized patients with bipolar disorder I (manic or mixed) in subpopulations (CN138-007). Eur Neuropsychopharmacol. 2010;20:776-783.

30. Findling RL, Nyilas M, Forbes RA, et al. Acute treatment of pediatric bipolar I disorder, manic or mixed episode, with aripiprazole: a randomized, double-blind, placebo-controlled study. J Clin Psychiatry. 2009;70(10):1441-1451.

31. Findling RL, Correll CU, Nyilas M, et al. Aripiprazole for the treatment of pediatric bipolar I disorder: a 30-week, randomized, placebo-controlled study. Bipolar Disord. 2013;15(2):138-149. 
32. Young AH, Oren DA, Lowy A, et al. Aripiprazole monotherapy in acute mania: 12-week randomised placebo- and haloperidol-controlled study. Br J Psychiatry. 2009;194(1):40-48.

33. Keck PE, Orsulak PJ, Cutler AJ, et al; CN138-135 Study Group. Aripiprazole monotherapy in the treatment of acute bipolar I mania: a randomized, double-blind, placebo- and lithium-controlled study. $J$ Affect Disord. 2009;112(1-3):36-49.

34. Vieta E, Bourin M, Sanchez R, et al; Aripiprazole Study Group. Effectiveness of aripiprazole v. haloperidol in acute bipolar mania: double-blind, randomised, comparative 12-week trial. Br J Psychiatry. 2005;187:235-242.

35. Singh M. Treatment efficacy and concomitant benzodiazepine use with aripiprazole versus olanzapine in acute bipolar mania. Eur Neuropsychopharmacol. 2009;19(3):S536.

36. Zimbroff DL, Marcus RN, Manos G, et al. Management of acute agitation in patients with bipolar disorder: efficacy and safety of intramuscular aripiprazole. J Clin Psychopharmacol. 2007;27(2): 171-176.

37. Vieta E, T'joen C, McQuade RD, et al. Efficacy of adjunctive aripiprazole to either valproate or lithium in bipolar mania patients partially nonresponsive to valproate/lithium monotherapy: a placebocontrolled study. Am J Psychiatry. 2008;165:1316-1325.

38. El-Mallakh RS, Marcus R, Baudelet C, McQuade R, Carson WH, Owen R. A 40-week double-blind aripiprazole versus lithium follow-up of a 12-week acute phase study (total 52 weeks) in bipolar I disorder. $J$ Affect Disord. 2012;136(3):258-266.

39. Marcus R, Khan A, Rollin L, et al. Efficacy of aripiprazole adjunctive to lithium or valproate in the long-term treatment of patients with bipolar I disorder with an inadequate response to lithium or valproate monotherapy: a multicenter, double-blind, randomized study. Bipolar Disord. 2011;13(2):133-144.

40. Vieta E, Owen R, Baudelet C, McQuade RD, Sanchez R, Marcus RN. Assessment of safety, tolerability and effectiveness of adjunctive aripiprazole to lithium/valproate in bipolar mania: a 46-week, open-label extension following a 6-week double-blind study. Curr Med Res Opin. 2010;26(6):1485-1496.

41. Carlson BX, Ketter TA, Sun W, et al. Aripiprazole in combination with lamotrigine for the long-term treatment of patients with bipolar I disorder (manic or mixed): a randomized, multicenter, double-blind study (CN138-392). Bipolar Disord. 2012;14(1):41-53.

42. Keck PE Jr, Calabrese JR, McQuade RD, et al; Aripiprazole Study Group. A randomized, double-blind, placebo-controlled 26-week trial of aripiprazole in recently manic patients with bipolar I disorder. J Clin Psychiatry. 2006;67(4):626-637.

43. Keck PE Jr, Calabrese JR, McIntyre RS, et al; Aripiprazole Study Group. Aripiprazole monotherapy for maintenance therapy in bipolar I disorder: a 100-week, double-blind study versus placebo. J Clin Psychiatry. 2007;68(10):1480-1491.

44. Fountoulakis KN, Vieta E, Schmidt F. Aripiprazole monotherapy in the treatment of bipolar disorder: a meta-analysis. J Affect Disord 2011;133(3):361-370.

45. Fountoulakis KN, Gonda X, Vieta E, Schmidt F. Treatment of psychotic symptoms in bipolar disorder with aripiprazole monotherapy: a meta-analysis. Ann Gen Psychiatry. 2009;8:27.

46. Cipriani A, Rendell JM, Geddes JR. Haloperidol alone or in combination for acute mania. Cochrane Database Syst Rev. 2006;3:CD004362.

47. Perlis RH, Welge JA, Vornik LA, Hirschfeld RM, KeckPE Jr. Atypical antipsychotics in the treatment of mania: a meta-analysis of randomized, placebo-controlled trials. J Clin Psychiatry. 2006;67:509-516.

48. Scherk H, Pajonk FG, Leucht S. Second-generation antipsychotic agents in the treatment of acute mania: a systematic review and meta-analysis of randomized controlled trials. Arch Gen Psychiatry. 2007;64: 442-455.

49. Smith LA, Cornelius V, WarnockA, Tacchi MJ, Taylor D. Pharmacological interventions for acute bipolar mania: a systematic review of randomized placebo-controlled trials. Bipolar Disord. 2007;9: 551-560.

50. Sachs GS, Gaulin BD, Gutierrez-Esteinou R, et al. Antimanic response to aripiprazole in bipolar I disorder patients is independent of the agitation level at baseline. J Clin Psychiatry. 2007;68:1377-1383.
51. Yildiz A, Vieta E, Leucht S, Baldessarini RJ. Efficacy of antimanic treatments: meta-analysis of randomized, controlled trials. Neuropsychopharmacology. 2011;36(2):375-389.

52. Muralidharan K, Ali M, Silveira LE, et al. Efficacy of second generation antipsychotics in treating acute mixed episodes in bipolar disorder: a meta-analysis of placebo-controlled trials. J Affect Disord. 2013;150(2):408-414.

53. Tohen M, Vieta E. Antipsychotic agents in the treatment of bipolar mania. Bipolar Disord. 2009;11 Suppl 2:45-54.

54. Kane JM, Sanchez R, Perry PP, et al. Aripiprazole intramuscular depot as maintenance treatment in patients with schizophrenia: a 52-week, multicenter, randomized, double-blind, placebo-controlled study. J Clin Psychiatry. 2012;73(5):617-624.

55. Dratcu L, Bobmanuel S, Davies W, et al. A UK panel consensus on the initiation of aripiprazole for the treatment of bipolar mania. Int $J$ Psychiatry Clin Pract. 2012;16(4):244-258.

56. Yatham LN, Kennedy SH, Parikh SV, et al. Canadian Network for Mood and Anxiety Treatments (CANMAT) and International Society for Bipolar Disorders (ISBD) collaborative update of CANMAT guidelines for the management of patients with bipolar disorder: update 2013. Bipolar Disord. 2013;15(1):1-44.

57. Goodwin GM; Consensus Group of the British Association for Psychopharmacology. Evidence-based guidelines for treating bipolar disorder: revised second edition - recommendations from the British Association for Psychopharmacology. J Psychopharmacol. 2009;23(4):346-388.

58. De Fazio P, Girardi P, Maina G, et al. Aripiprazole in acute mania and long-term treatment of bipolar disorder: a critical review by an Italian working group. Clin Drug Investig. 2010;30(12):827-841.

59. Bristol-Myers-Squibb. OPEN. Abilify (aripiprazole) Summary of Product Characteristics. Sep 2011.

60. Kane JM, Barnes TR, Correll CU, et al. Evaluation of akathisia in patients with schizophrenia, schizoaffective disorder, or bipolar I disorder: a post hoc analysis of pooled data from short- and long-term aripiprazole trials. J Psychopharmacol. 2010;24(7):1019-1029.

61. Dhillon S. Aripiprazole: a review of its use in the management of mania in adults with bipolar I disorder. Drugs. 2012;72(1):133-162.

62. Correll CU, Manu P, Olshanskiy V, Napolitano B, Kane JM, Malhotra AK. Cardiometabolic risk of second-generation antipsychotic medications during first-time use in children and adolescents. JAMA. 2009;302(16): 1765-1773.

63. Fagiolini A, Frank E, Scott JA, Turkin S, Kupfer DJ. Metabolic syndrome in bipolar disorder: findings from the Bipolar Disorder Center for Pennsylvanians. Bipolar Disord. 2005;7(5):424-430.

64. American Diabetes Association; American Psychiatric Association; American Association of Clinical Endocrinologists; North American Association for the Study of Obesity. Consensus development conference on antipsychotic drugs and obesity and diabetes. Diabetes Care. 2004;27(2):596-601.

65. Kemp DE, Calabrese JR, Tran QV, Pikalov A, Eudicone JM, Baker RA. Metabolic syndrome in patients enrolled in a clinical trial of aripiprazole in the maintenance treatment of bipolar I disorder: a post hoc analysis of a randomized, double-blind, placebo-controlled trial. J Clin Psychiatry. 2010;71(9):1138-1144.

66. Young AH, Grunze H. Physical health of patients with bipolar disorder. Acta Psychiatr Scand Suppl. 2013;442:3-10.

67. Vieta E, Murru A, Pueyo MJ. [Guidelines on the management of bipolar disorder in Catalunya]. Barcelona: Department of Health. Available from: http://www.gencat.cat/salut/depsan/units/aatrm/pdf/guia_trastorn_ bipolar_aiaqs_2010ca.pdf. Accessed January 17, 2014. Catalan.

68. Colom F, Vieta E, Daban C, Pacchiarotti I, Sanchez-Moreno J. Clinical and therapeutic implications of predominant polarity in bipolar disorder. J Affect Disord. 2006;93:13-17. 


\section{Publish your work in this journal}

Neuropsychiatric Disease and Treatment is an international, peerreviewed journal of clinical therapeutics and pharmacology focusing on concise rapid reporting of clinical or pre-clinical studies on a range of neuropsychiatric and neurological disorders. This journal is indexed on PubMed Central, the 'PsycINFO' database and CAS.

The manuscript management system is completely online and includes a very quick and fair peer-review system, which is all easy to use. Visit http://www.dovepress.com/testimonials.php to read real quotes from published authors.

\footnotetext{
Submit your manuscript here: http://www.dovepress.com/neuropsychiatric-disease-and-treatment-journal
} 